\title{
CONSÓRCIOS PÚBLICOS DE RESÍDUOS SÓLIDOS URBANOS NA PERSPECTIVA REGIONAL DO PARANÁ
}

\section{CONSORTIUM OF PUBLIC MUNICIPAL SOLID WASTE IN REGIONAL PERSPECTIVE OF PARANA}

\author{
Priscila Alves dos Anjos \\ Companhia de Saneamento do Paraná - Londrina - PR - Brasil \\ Karen Juliana do Amaral \\ Universidade de Stuttgart - Stuttgart - Alemanha \\ Klaus Martin Fischer \\ Universidade de Stuttgart - Stuttgart - Alemanha
}

\begin{abstract}
Resumo: O Consórcio Público pode ser uma alternativa viável para atendimento às atuais exigências do cenário de saneamento básico. Assim, o objetivo geral desta pesquisa foi analisar o processo de formação de novos consórcios públicos intermunicipais de resíduos sólidos urbanos, utilizando como estudo de caso o Estado do Paraná. A metodologia baseou-se em pesquisa bibliográfica e de campo. Para a amostra, selecionou-se o grupo de municípios do Consórcio Intermunicipal para Gestão de Resíduos Sólidos Urbanos - CONRESOL e um grupo de municípios não consorciados. Foram aplicados questionários para representantes dos dois grupos. Entre os resultados, pode-se apontar a iniciativa do município como fundamental no processo da formação de novos consórcios; o trâmite jurídico para a implantação do consórcio representando mais segurança jurídica do que um empecilho; e a viabilização da disposição adequada à maior vantagem na formação desse arranjo.
\end{abstract}

Palavras-chave: Resíduos Sólidos Urbanos. Consórcios Públicos. Disposição Adequada.

Abstract: The Public Consortium can be a viable alternative to meet the current demands of sanitation scenario. The objective of this research was to analyze the process of formation of new public consortia of municipal solid waste, using as a case study the state of Paraná. The methodology was based on a literature review and field research. The group of municipalities of the Intermunicipal Consortium for Management of Municipal Solid Waste (CONRESOL) and a group of not associated municipalities were selected as sample. Questionnaires were applied to the two groups. Among the results one can point the initiative of the municipality as fundamental in the process of formation of new consortia; the legal process for the 
formation of consortium representing more a legal certainty than a hindrance; and the feasibility of appropriate disposition the greatest advantage in the forming of this arrangement.

Keywords: Solid Waste. Public Consortia. Apropriate Disposal.

\section{Introdução}

Os avanços da industrialização e do consumo implicam no aumento da geração e complexidade dos Resíduos Sólidos Urbanos RSUs em todo o mundo, desafiam os limites de sustentabilidade do planeta pelos impactos ambientais que causam; contribuem para o agravamento de problemas sanitários e conciliados com uma legislação cada vez mais rígida; exigem sistemas mais eficientes de gestão, resultando em custos mais altos para a prestação de serviços de limpeza urbana e manejo de resíduos sólidos.

O gerenciamento dos RSUs, desde sua produção, coleta e disposição final, representa um desafio aos municípios. A solução regional representa ganho no custo de investimentos e de operação com o compartilhamento de instalações e, ao mesmo tempo, é conveniente aos municípios que têm dificuldades para operar sozinhos um aterro sanitário (BRASIL, 2010c).

O federalismo cooperativo previsto na Lei de Consórcios Públicos é um instrumento para equacionar problemas enfrentados pelas Administrações Públicas, dentre os quais, a prestação de serviços de manejo de resíduos sólidos municipais de forma adequada à Lei $\mathrm{n}$. 12.305/2010, a qual prevê o encerramento dos lixões, implantação da coleta seletiva, da logística reversa e da compostagem dos resíduos orgânicos (BRASIL, 2010a). No entanto, a maioria dos municípios enfrenta dificuldades para atender aos novos paradigmas estabelecidos, tanto pela insuficiência de recursos orçamentários quanto pela falta de quadro técnico com profissionais especializados.

Acredita-se que a utilização dos consórcios públicos como instrumento da gestão associada no setor de saneamento representa um avanço na política de cooperação intergovernamental, e que pode trazer benefícios, tais como a racionalização do uso dos recursos destinados ao planejamento, regulação, programação, fiscalização e consecução dos objetivos comuns contratados (CHIECO, 2011). 
A constituição de consórcios públicos para a prestação de serviços de resíduos sólidos pode ser uma forma viável e relevante face ao cenário de saneamento básico no Brasil, o qual apresenta indicadores preocupantes, tais como, a média per capita de resíduos gerados de $1,05 \mathrm{~kg} / \mathrm{hab}$./dia e a disposição inadequada (lixões e aterros controlados) em mais de $74 \%$ dos municípios (BRASIL, 2016).

Dessa forma, esta pesquisa buscou compreender os possíveis motivos que desfavorecem a formação de novos consórcios nessa área, apresentar recomendações que fortaleçam a proposta de consórcios públicos de RSU e, ao mesmo tempo, contribuir com pesquisas afins, utilizando como estudo de caso o Estado do Paraná.

A amostra da pesquisa delimitou-se ao grupo dos 21 municípios do Consórcio Intermunicipal para Gestão de Resíduos Sólidos Urbanos de Curitiba e Região Metropolitana (CONRESOL): Agudos do Sul, Almirante Tamandaré, Araucária, Balsa Nova, Bocaiúva do Sul, Campina Grande do Sul, Campo Largo, Campo Magro, Colombo, Contenda, Curitiba, Fazenda Rio Grande, Mandirituba, Piên, Pinhais, Piraquara, Quatro Barras, Quitandinha, São José dos Pinhais, Tijucas do Sul e Tunas do Paraná; e um grupo de 15 municípios não consorciados e pertencentes às demais regiões metropolitanas do Paraná: Alto Piquiri, Arapongas, Assai, Astorga, Cruzeiro do Oeste, Iporã, Lobato, Londrina, Maringá, Nova Olímpia, Primeiro de Maio, Rolândia, Sabáudia, Santa Fé e Umuarama.

Com base nos dados do Sistema Nacional de Informações sobre Saneamento - SNIS 2014 (BRASIL, 2016), é válido afirmar que o Estado do Paraná apresenta desafios na gestão de resíduos sólidos similares ao âmbito nacional, como a necessidade de erradicar os lixões. Por outro lado, apresenta alguns dados mais satisfatórios do que a média nacional, como a disposição adequada, que é de $26 \%$ para o Brasil e no Paraná chega a $45 \%$, com $50 \%$ para o Rio Grande do Sul e $65 \%$ para o Estado de Santa Catarina.

Quanto à geração per capita de resíduos gerados no Brasil, o Paraná apresenta $0,84 \mathrm{~kg} / \mathrm{hab}$./dia, Rio Grande do Sul também 0,84kg/hab./dia e Santa Catarina 0,80 kg/hab./dia, enquanto outros 19 estados apresentam o valor médio per capita superior, com destaque para o Estado do Ceará, que apresenta o número $1,69 \mathrm{~kg} / \mathrm{hab}$./dia (BRASIL, 2016). 
Em relação aos municípios estudados, o grupo do CONRESOL abrange um terço da população paranaense, mais de 3 milhões de habitantes, e pertence a uma região metropolitana instituída na década de 1970; já o grupo dos municípios não consorciados pertence às regiões metropolitanas de Londrina e Maringá, criadas na década de 1990, e Umuarama, instituída em 2012, e totalizam 1,2 milhões de habitantes, conforme a caracterização apresentada nos resultados e discussão deste artigo.

Nesse contexto, a questão é por que a formação de consórcios públicos intermunicipais de resíduos sólidos ainda não se consolidou no Paraná?

O presente artigo, que busca responder essa questão, está estruturado em sete partes, a saber: Introdução; Indicadores gerais de resíduos sólidos urbanos no Brasil e no Paraná; Aspecto Legal; Materiais e Métodos; Resultados e Discussão - Levantamento dos Consórcios de Resíduos, Caracterização do CONRESOL e do Grupo de Municípios não Consorciados e Resultados da Pesquisa de Campo; e Considerações Finais.

\section{Indicadores gerais de RSU no Brasil e no Paraná}

Com base no SNIS 2014 (BRASIL, 2016), pode-se afirmar que o serviço de coleta domiciliar no Brasil alcança a média de quase $100 \%$ nos municípios, enquanto os dados da ABRELPE (2014) indicam a cobertura de coleta domiciliar de 90,68\%. Embora esse indicador apresente-se elevado, não existe uma avaliação da qualidade desse serviço. Conforme Silva (2014), o não atendimento da coleta a $100 \%$ da área urbana, bem como a demanda por mais aterros, são problemas básicos que ainda persistem embora exista um sistema de reaproveitamento em capitais do país.

Sobre a coleta seletiva, segundo o SNIS 2014, esta é praticada em $35,1 \%$ dos municípios participantes da pesquisa, o que representa $23,7 \%$ do total de municípios do País (BRASIL, 2016). A pesquisa da Associação Brasileira de Empresas de Limpeza Pública e Resíduos Especiais - Abrelpe apresenta, para 2014, um percentual mais positivo, com a projeção de 3.608 municípios com iniciativas de coleta seletiva, ou seja, aproximadamente $65 \%$ dos municípios brasileiros (ABRELPE, 
2014). Apesar do percentual expressivo, muitas vezes as atividades resumem-se à disponibilização de pontos de entrega voluntária ou convênios com cooperativas de catadores que não abrangem a totalidade do território ou da população do município.

No tocante à massa coletada de Resíduos Sólidos Domiciliares RDOs e Resíduos Sólidos Públicos - RPUs, para os municípios participantes da pesquisa, identificou-se a quantidade de 55,9 milhões de toneladas no ano, o que permitiu estimar para o país o valor de 64,4 milhões de toneladas de resíduos coletados no ano (BRASIL, 2016). Os dados da ABRELPE (2014) indicam que a quantidade de resíduos coletados em 2014 ultrapassou 71 milhões de toneladas.

Com relação à geração de resíduos, a pesquisa do SNIS indicou que os resíduos produzidos resultaram em uma massa média per capita de $0,83 \mathrm{~kg} / \mathrm{hab} /$ dia na Região Sul até $1,26 \mathrm{~kg} / \mathrm{hab} / \mathrm{dia}$ na Região Centro-Oeste, encontrando-se o valor médio para o país de 1,05 $\mathrm{kg} / \mathrm{hab} /$ dia (BRASIL, 2014). Acrescente-se que a ABRELPE apresenta para 2014 o índice de $1,062 \mathrm{~kg} / \mathrm{hab} /$ dia.

Quanto à disposição final dos resíduos, o SNIS 2014 apresentou, entre as 2.705 unidades por disposição no solo, 26\% dos municípios com aterros sanitários, $26 \%$ com aterros controlados e $48 \%$ com lixões (BRASIL, 2016). A ABRELPE apresentou os percentuais de: $40 \%$ para aterros sanitários, 32\% para aterros controlados e $28 \%$ para lixões. Vale comentar que, para o ano de 2012, a ABRELPE divulgou a composição média dos resíduos domiciliares coletados em 51,4\% materiais orgânicos, 31,9\% recicláveis e 16,7\% rejeitos (ABRELPE, 2012).

Em relação à cobrança pela prestação dos serviços, aproximadamente $40 \%$ dos municípios afirmou realizar. Já quanto à forma de cobrança desses serviços, verifica-se que a inserção de taxa no boleto do Imposto Predial e Territorial Urbano - IPTU é a forma generalizada de execução, representa $88,3 \%$ dos casos, seguida da taxa no boleto do serviço de abastecimento de água, com $7,7 \%$, enquanto a incidência da taxa em boleto específico é igual a $2,6 \%$, e outras formas, por exemplo, via boleto de energia elétrica, aparece com 1,2\% dos casos (BRASIL, 2014).

Com base no Quadro 1, pode-se observar que o cenário de resíduos sólidos no âmbito nacional apresenta aspectos preocupantes, 
como a quantidade de resíduos sólidos gerada e a disposição inadequada presente na maioria dos municípios.

Quadro 1. Síntese do cenário de resíduos sólidos no Brasil

\begin{tabular}{|c|c|c|c|}
\hline & Indicadores & Valores & Fonte \\
\hline \multirow{3}{*}{ 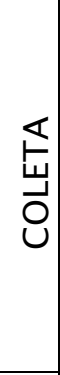 } & $\begin{array}{l}\text { Taxa de cobertura de coleta } \\
\text { domiciliar }\end{array}$ & $98,6 \%$ indicador médio & $\begin{array}{c}\text { SNIS } 2014 \\
\text { (BRASIL, 2016) }\end{array}$ \\
\hline & $\begin{array}{l}\text { Massa coletada de resíduos } \\
\text { sólidos domiciliares e } \\
\text { públicos (RDO+RPU) }\end{array}$ & $\begin{array}{l}\text { Média per capita de 1,05 } \\
\mathrm{kg} / \mathrm{hab} / \text { dia }\end{array}$ & $\begin{array}{c}\text { SNIS } 2014 \\
\text { (BRASIL, 2016) }\end{array}$ \\
\hline & Coleta seletiva & $23,7 \%$ dos municípios & $\begin{array}{c}\text { SNIS } 2014 \\
\text { (BRASIL, 2016) }\end{array}$ \\
\hline \multirow{3}{*}{$\begin{array}{l}0 \\
\frac{0}{4} \\
\bar{\cup} \\
0 \\
\frac{1}{0} \\
口\end{array}$} & $\begin{array}{l}\text { Composição média dos RSU } \\
\text { coletados }\end{array}$ & $\begin{array}{l}51,4 \% \text { materiais orgânicos } \\
31,9 \% \text { recicláveis } \\
16,7 \% \text { rejeitos }\end{array}$ & ABRELPE 2012 \\
\hline & \multirow{2}{*}{ Disposição final } & $\begin{array}{l}26 \% \text { aterros sanitários } \\
26 \% \text { aterros controlados } \\
48 \% \text { lixões }\end{array}$ & $\begin{array}{c}\text { SNIS } 2014 \\
(\text { BRASIL, 2016) }\end{array}$ \\
\hline & & $\begin{array}{l}40 \% \text { aterros sanitários } \\
32 \% \text { aterros controlados } \\
28 \% \text { lixões }\end{array}$ & ABRELPE 2014 \\
\hline 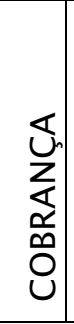 & $\begin{array}{l}\text { Cobrança pelos serviços de } \\
\text { manejo de RSU } \\
\text { Forma de cobrança }\end{array}$ & $\begin{array}{l}40 \% \text { dos municípios } \\
88,3 \% \text { taxa no IPTU } \\
7,7 \% \text { taxa na fatura de } \\
\text { água } \\
2,6 \% \text { boleto específico } \\
1,2 \% \text { outras formas }\end{array}$ & $\begin{array}{c}\text { SNIS } 2014 \\
\text { (BRASIL, 2016) }\end{array}$ \\
\hline
\end{tabular}

Fonte: Adaptado de Brasil (2016), Abrelpe (2012) e Abrelpe (2014).

No Paraná, a taxa de cobertura de coleta domiciliar fica em torno de $94 \%$ e a coleta seletiva está implantada em mais de $50 \%$ dos municípios (PARANÁ, 2013).

Em relação à geração média per capita, o valor é de aproximadamente $0,9 \mathrm{~kg} / \mathrm{hab} /$ dia (PARANÁ, 2013), referência coerente com o valor médio nacional de $0,84 \mathrm{~kg} / \mathrm{hab}$./dia apontado pelo SNIS 2014 e abaixo do valor nacional de $1,062 \mathrm{~kg} / \mathrm{hab}$./dia apresentado pela ABRELPE (2014), a qual apresenta para o Paraná o índice de 0,792 $\mathrm{kg} / \mathrm{hab}$./dia.

Quanto à disposição final dos resíduos, $58,65 \%$ dos municípios realizam a disposição adequada e $41,35 \%$ realizam a disposição inadequada (PARANÁ, 2013). Cabe mencionar que a ABRELPE (2014) 
apresenta para o Paraná o índice de $70,2 \%$ de resíduos coletados e dispostos de forma adequada.

Sobre a caracterização dos RSUs, a composição média dos resíduos domiciliares coletados no Paraná é de 56,5\% de materiais orgânicos, 26\% de recicláveis e 17,5\% de rejeitos (PARANÁ, 2013).

Em relação ao custo de serviços e estrutura tarifária, 53,3\% das cidades do Paraná cobram pelos serviços de limpeza pública e manejo de resíduos sólidos. Quanto à forma de cobrança, 74,12\% realizam por meio do IPTU, 18,82\% na conta de água, o restante realiza de outras formas (PARANÁ, 2013).

O Quadro 2 - indicadores de resíduos no Paraná - apresenta aspectos similares ao cenário nacional: tendência de crescimento na quantidade de resíduos gerados; mais de $50 \%$ de resíduos orgânicos dispostos em aterros; necessidade de incrementar a coleta seletiva e disposição inadequada em torno de $40 \%$; aproximadamente $50 \%$ dos municípios praticam a cobrança pela prestação dos serviços de manejo de resíduos sólidos, sendo a forma de cobrança mais usual por meio do IPTU. Cabe destacar que existe alto grau de inadimplência no pagamento do IPTU, ou seja, os municípios, por um lado, têm dificuldades para gerenciar adequadamente o sistema de resíduos sólidos e, por outro lado, não arrecadam recursos suficientes para a prestação desses serviços. 
Quadro 2. Síntese do cenário dos resíduos sólidos no Paraná

\begin{tabular}{|c|c|c|}
\hline & Indicadores & Valores \\
\hline \multirow{4}{*}{ 岕 } & Taxa de cobertura de coleta domiciliar & $94 \%$ \\
\hline & $\begin{array}{l}\text { Massa coletada de resíduos sólidos } \\
\text { domiciliares e públicos (RDO+RPU) }\end{array}$ & $\begin{array}{l}\text { Média per capita de } 0,9 \\
\mathrm{~kg} / \mathrm{hab} \text {. dia }\end{array}$ \\
\hline & Coleta seletiva & 53,38\% dos municípios \\
\hline & Composição média dos RSU coletados & $\begin{array}{l}56,5 \% \text { materiais orgânicos } \\
26 \% \text { recicláveis } \\
17,5 \% \text { rejeitos }\end{array}$ \\
\hline 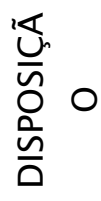 & Disposição final & $\begin{array}{l}58,65 \% \text { disposição adequada } \\
41,35 \% \text { disposição inadequada }\end{array}$ \\
\hline 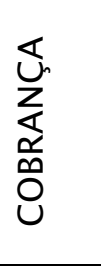 & $\begin{array}{l}\text { Cobrança pelos serviços de manejo de } \\
\text { RSU } \\
\text { Forma de cobrança }\end{array}$ & $\begin{array}{l}53,3 \% \text { dos municípios } \\
74,12 \% \text { taxa no IPTU } \\
18,82 \% \text { taxa na fatura de água } \\
7,06 \% \text { outras formas }\end{array}$ \\
\hline
\end{tabular}

Fonte: Adaptado de Paraná (2013).

O cenário dos resíduos sólidos aponta a necessidade de formas de gestão mais eficientes. De acordo com Pinho (2011), a gestão de resíduos sólidos é fundamental para o desenvolvimento urbano e regional, influencia a qualidade de vida da população e representa um elo entre a saúde pública e a sustentabilidade ambiental.

Acrescente-se que os aterros sanitários exigem investimentos considerados altos para a maioria dos municípios brasileiros, assim, o consórcio público intermunicipal é um arranjo regionalizado para o atendimento às exigências impostas pela Lei n. 12.305/2010. Segundo Ceccon (2009), a relação entre diferentes instituições de diferentes municípios, cada qual com vontades políticas, desejos econômicos e interesses sociais distintos é o que torna o consórcio uma alternativa relevante, todavia complexa.

\section{Aspecto legal}


Pode-se afirmar que o Brasil possui um arcabouço legal que estabelece diretrizes para a condução das questões ambientais e que contribuem para o enfrentamento da problemática dos resíduos sólidos, por exemplo: Política Nacional de Meio Ambiente - PNMA (BRASIL, 1981); Lei de Crimes Ambientais (BRASIL,1998); e Política Nacional de Recursos Hídricos - PNRH (BRASIL, 1997). 
Essas leis, entre outras, precederam o marco regulatório para a gestão dos resíduos sólidos, o qual é composto pela Política Nacional de Resíduos Sólidos - PNRS (Lei n. 12.305/2010); pela Lei Federal de Saneamento Básico (Lei n. 11.445/2007), que prevê a prestação dos serviços públicos de limpeza urbana e manejo de resíduos sólidos; e por meio da Lei de Consórcios Públicos (Lei n. 11.107/2005), que permite relações de cooperação federativa para a prestação desses serviços. A Lei n. $11.107 / 2005$, lei de consórcios públicos, regulamentada pelo Decreto n. 6.017, de 17 de janeiro de 2007, dispõe sobre normas gerais para a União, os Estados, o Distrito Federal e os Municípios contratarem consórcios públicos para a realização de objetivos de interesse comum (BRASIL, 2005).

Os Consórcios entre municípios ganharam espaço na década de 1980 como reflexo da promulgação da Constituição Federal de 1988 (CFB), quando os municípios passaram a assumir responsabilidades que eram do Estado e da União em diversos setores - saúde, educação, segurança, preservação ambiental, porém, o processo de descentralização não foi acompanhado pela divisão de recursos, criando-se uma disparidade (CALDERAN et al. 2012).

Conforme Batista (2011c), os Consórcios Administrativos tinham previsão legal na Emenda Constitucional n. 1/1969. Assim, várias experiências tiveram início nesse período, porém, consideradas pactos de cooperação de natureza precária. No final da década de 1990, a Emenda Constitucional n. 19/1998 modifica a redação do Artigo 241 da CFB. O Consórcio Público passa a figurar no ordenamento jurídico e criam-se condições para uma Lei de abrangência nacional para regulamentação dos Consórcios Públicos.

No ano de 2005, aprovou-se a Lei n. 11.107/2005. A partir desse diploma que regulamentou o artigo 241 da CFB, os Consórcios Públicos podem ser constituídos com personalidade jurídica de direito público quando se constituir numa Associação Pública, espécie de autarquia interfederativa, ou pessoa jurídica de direito privado sem fins lucrativos, e regidos pelos preceitos da Administração Pública (BATISTA, $2011 \mathrm{c}$ ).

O Fluxograma 1 apresenta as etapas requeridas para a constituição de um Consórcio Público. 
Fluxograma 1. Etapas Da Constituição Do Consórcio Público

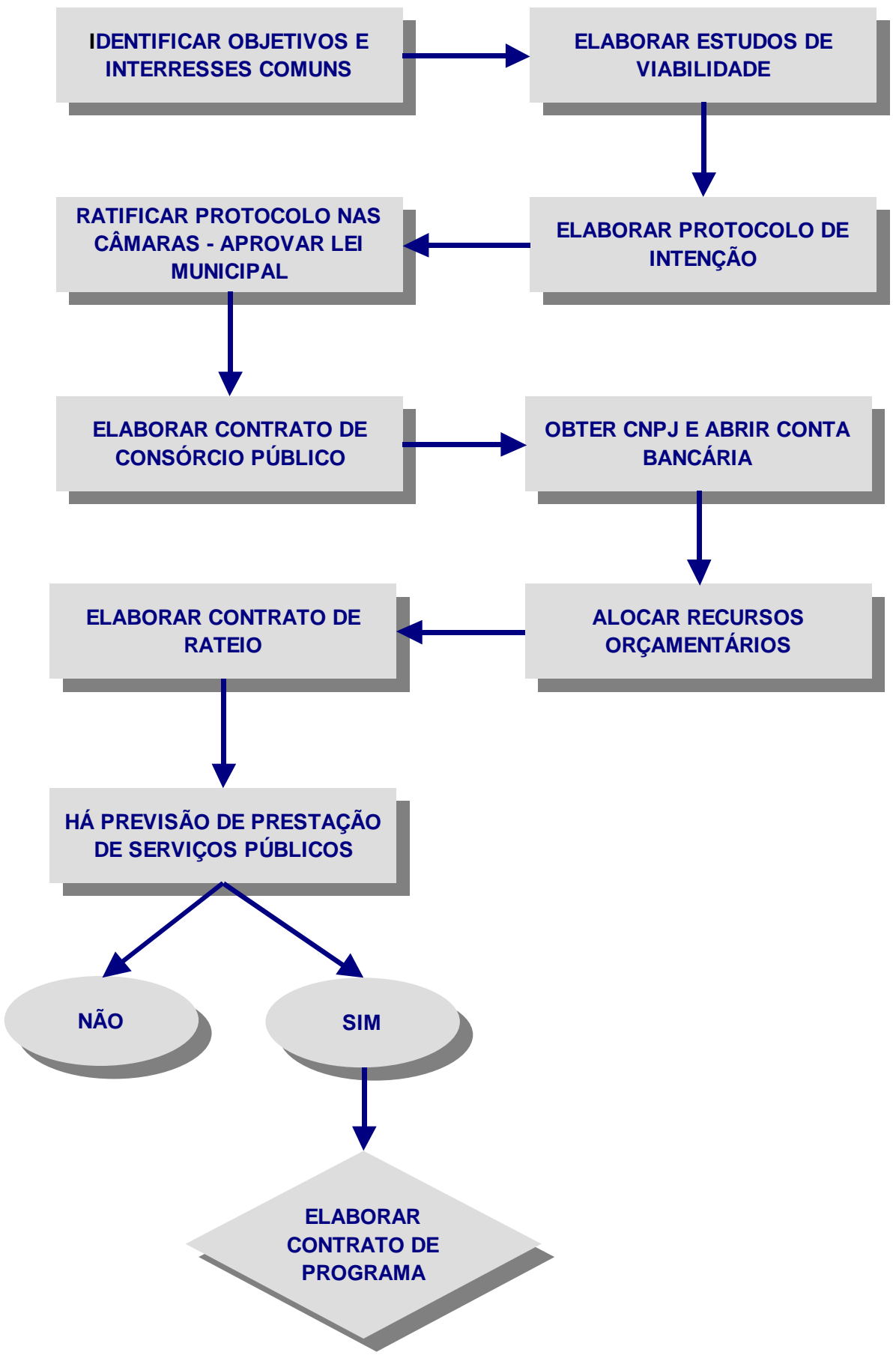

Fonte: Adaptado de Batista (2011b).

A primeira etapa é feita a partir do levantamento da situação dos municípios. Esse diagnóstico é sucedido pelo detalhamento da proposta do consórcio, com dimensionamentos quantitativos, definição de custos necessários, tecnologias adequadas e prazos, estudos de viabilidade 
técnica, que serão a base para a elaboração do Protocolo de Intenções (BATISTA, $2011 \mathrm{~b}$ ).

Juridicamente o Protocolo de Intenções é o documento que inicia o processo de constituição de um Consórcio Público, no qual devem constar os aspectos jurídicos e técnicos. Uma vez formalizado, o documento deverá ser subscrito pelos prefeitos e publicado (CHIECO, 2011).

O Contrato de Consórcio, que se inicia com o Protocolo de Intenções, autoriza a gestão associada de serviços públicos, explicita as competências a serem transferidas ao consórcio público, o território em que serão prestados os serviços especificados, define as condições para o Contrato de Programa, entre outros (BRASIL, 2010c).

Após, deve-se providenciar a obtenção do Cadastro Nacional de Pessoa Jurídica - CNPJ e abertura de conta bancária para o consórcio. Os municípios participantes deverão fazer previsão orçamentária das atividades do consórcio, a qual deve ser prevista na Lei Orçamentária Anual - LOA de cada ente consorciado, para a assinatura do Contrato de Rateio, instrumento firmado anualmente, por meio do qual os consorciados repassarão recursos ao Consórcio Público (BATISTA, 2011c).

A Lei n. 11.445/2007, lei de saneamento básico, regulamentada pelo Decreto 7.217, de 21 de junho de 2010, instituiu a Política Nacional de Saneamento Básico - PNSB e definiu saneamento básico como o conjunto de serviços e instalações operacionais de abastecimento de água potável; esgotamento sanitário; limpeza urbana e manejo de resíduos sólidos; e drenagem e manejo de águas pluviais urbanas (BRASIL, 2007).

A referida lei estabeleceu que a limpeza urbana e manejo de resíduos sólidos compreendem o conjunto de atividades e instalações operacionais de coleta, transporte, transbordo, tratamento e destino final do lixo doméstico e do lixo originário da varrição e limpeza de logradouros e vias públicas (BRASIL, 2007).

A Lei n. 11.445/2007 também define que a prestação dos serviços públicos de saneamento básico observará os planos municipais de saneamento básico, que são indispensáveis e obrigatórios para a contratação ou concessão dos serviços. Em seu Art. $3^{\circ}$, inciso II, a lei 
define a gestão associada como uma associação voluntária de entes federados, por convênio de cooperação ou consórcio público, conforme disposto no art. 241 da Constituição Federal (BRASIL, 2010b).

Por meio dessa lei, institui-se o planejamento, a regulação e fiscalização; a prestação de serviços com regras; a exigência de contratos precedidos de estudo de viabilidade técnica e financeira; definição de regulamento por lei; definição de entidade de regulação e controle social assegurado (BRASIL, 2010c).

Pode-se afirmar que a Lei 11.445/2007, Lei do Saneamento, representa um avanço para o saneamento no país, pela regulação do setor, busca da universalização dos serviços correlatos e da melhoria da qualidade da prestação desses serviços, com a participação social; também prevê a prestação de serviços de saneamento sob a forma consorciada e, no artigo 48, cita como diretriz o estímulo à implementação de infraestruturas e serviços comuns a municípios, mediante mecanismos de cooperação entre entes federados, portanto, complementa a proposta da Lei n. 11.107/2005.

A Lei n. 12.305/2010, lei de resíduos sólidos, regulamentada pelo Decreto 7.404, de 23 de dezembro de 2010, instituiu a Política Nacional de Resíduos Sólidos - PNRS, com a definição de princípios, objetivos, instrumentos, metas, ações e diretrizes para a gestão integrada e gerenciamento dos resíduos sólidos, com a previsão das responsabilidades dos geradores e do poder público (BRASIL, 2010a).

Entre diversos objetivos estabelecidos por esta Lei, no artigo sétimo estão: a ordem de prioridade para a gestão dos resíduos - não geração, redução, reutilização, reciclagem, tratamento dos resíduos sólidos e disposição final ambientalmente adequada dos rejeitos; e regularidade, continuidade, funcionalidade e universalização da prestação dos serviços públicos de limpeza urbana e de manejo de resíduos sólidos, com a adoção de mecanismos que assegurem a recuperação dos custos dos serviços prestados, para garantir a sustentabilidade operacional e financeira do sistema, de acordo com a Lei n. $11.445 / 2007$ (BRASIL, 2010a).

Entre os instrumentos definidos pela Lei n. 12.305/2010, no artigo oitavo, estão os planos de resíduos sólidos, a coleta seletiva, os sistemas de logística reversa, o incentivo à criação e ao desenvolvimento 
de cooperativas e outras formas de associação dos catadores de materiais recicláveis, a educação ambiental, e o Sistema Nacional de Informações sobre a Gestão dos Resíduos Sólidos - SINIR (BRASIL, 2010a).

A Lei n. 12.305/2010, além de prever a forma consorciada na prestação dos serviços de resíduos sólidos, no artigo 45, destaca que esse tipo de arranjo institucional tem prioridade na obtenção de incentivos instituídos pelo governo federal. Assim, reforça a proposta de consórcios públicos intermunicipais, os quais possibilitam a cooperação dos municípios para ganho de escala, melhoria de capacidade técnica e financeira, bem como a sustentabilidade do desenvolvimento regional.

\section{Material e métodos}

A pesquisa contemplou a revisão da literatura existente sobre o assunto, da legislação aplicável ao tema e a realização de pesquisa de campo, para constituir um estudo de caso no Estado do Paraná, o qual foi realizado com base no Fluxograma 2. 
Fluxograma 2. Etapas metodológicas da pesquisa

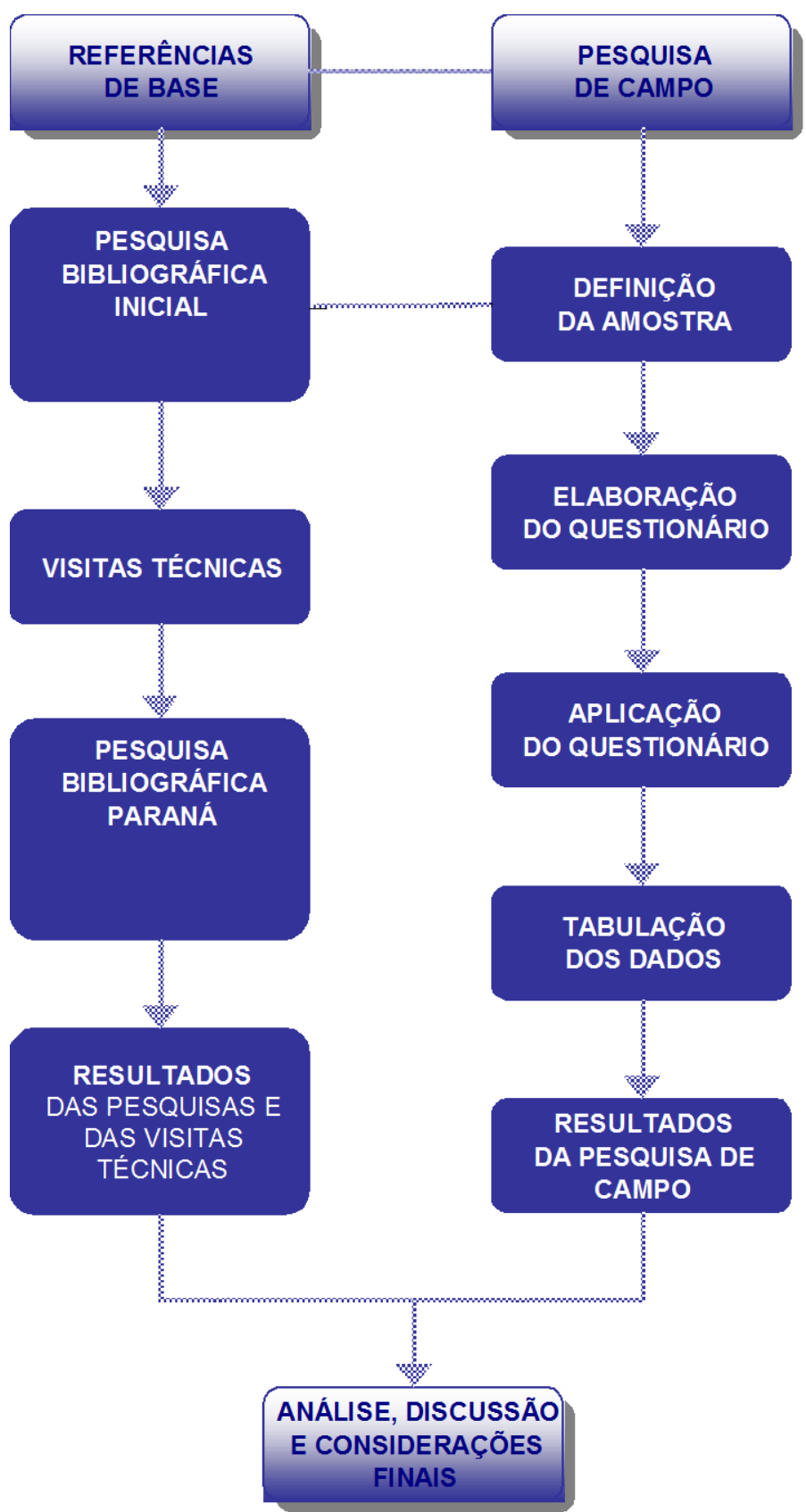

Fonte: Elaborado pela autora..

Para a pesquisa bibliográfica inicial sobre o tema RSU e consórcios públicos intermunicipais, consultou-se livros, artigos e legislação pertinente. $\mathrm{Na}$ etapa seguinte, para definição do escopo da pesquisa, buscou-se identificar os consórcios de resíduos sólidos implantados no Brasil a partir de consultas on line em sites de instituições que apresentam bases de dados oficiais, tais como, Instituto Brasileiro de Geografia e Estatística - IBGE, Instituto Paranaense de Desenvolvimento 
Econômico e Social - IPARDES e Instituto de Pesquisa Econômica Aplicada - IPEA.

Depois da delimitação do Paraná como escopo da pesquisa, para a obtenção de informações e documentos mais específicos, foram realizados contatos com instituições que tratam da questão de Consórcios Públicos de Resíduos Sólidos no Paraná: Diretoria de Resíduos Sólidos do Instituto das Águas do Paraná - IPAGUAS, que é a Agência Reguladora da prestação de serviços de saneamento no Paraná, Departamento de Resíduos Sólidos da Secretaria Estadual de Meio Ambiente - SEMA e a Gerência do CONRESOL.

A pesquisa de campo consistiu na definição da amostra da pesquisa, na elaboração e aplicação do questionário para o grupo de municípios do CONRESOL e para um grupo de municípios paranaenses não consorciados, tabulação dos dados e a análise dos resultados.

Quanto à definição da amostra, primeiramente buscou-se identificar e quantificar os consórcios públicos de resíduos sólidos implantados no Brasil, porém, constatou-se indisponibilidade dessas informações de forma sistematizada. As bases de dados localizadas foram um levantamento realizado pela Caixa Econômica Federal - CEF em 2011 (BATISTA, 2011 a) e o Sistema Nacional de Informações sobre Saneamento (SNIS): diagnóstico do manejo de resíduos sólidos urbanos2010 (BRASIL, 2012). A partir da análise dessas bases de dados, inicialmente selecionou-se a Região Sul, alternativa que se mostrou inadequada pelo universo muito grande da amostra e inconsistência de algumas informações, que serão apresentadas nos resultados.

Dessa forma, o escopo da pesquisa foi limitado ao Estado do Paraná, pela maior disponibilidade de informações e possibilidade de averiguação destas. Para a definição da amostra da pesquisa, definiu-se estudar um grupo de municípios consorciados - CONRESOL e um grupo de municípios não consorciados.

A escolha do CONRESOL foi devida a sua representatividade no Estado, o qual concentra um terço da população paranaense, incluindo a capital do Estado, e além disso, o aterro que atende ao Consórcio recebe uma quantidade significativa de resíduos, em média 2.400 toneladas de resíduos/dia. O grupo de municípios da região metropolitana de Curitiba - RMC que integra o CONRESOL totaliza 21 municípios para a amostra dos municípios consorciados, sendo que, a RMC, instituída pela 
Lei Complementar $\mathrm{n}^{\circ} 14$, de 8 de junho de 1973, atualmente compreende 29 municípios.

Quanto à definição do grupo dos municípios não consorciados no Paraná, um dos critérios adotados, considerando que o CONRESOL agrega municípios da região metropolitana - RM, foi selecionar municípios de outras regiões metropolitanas do Estado, que são: Região Metropolitana de Londrina - RMLO, instituída pela Lei Complementar 81, de 17 de julho de 1998 (PARANÁ, 1998a); Região Metropolitana de Maringá (RMM), instituída pela Lei Complementar 83, de 17 de junho de 1998 (PARANÁ, 1998b); e Região Metropolitana de Umuarama (RMUM), instituída pela Lei Complementar 149, de 22 de agosto de 2012 (PARANÁ, 2012). Outro critério adotado para essa amostra foi selecionar os municípios de maior porte em cada região metropolitana e que participaram da pesquisa do SNIS 2010 (BRASIL, 2012), considerando-se a disponibilidade de indicadores de resíduos sólidos, de modo a permitir a comparação entre este grupo e o grupo de municípios do CONRESOL.

Assim, foi possível selecionar 15 municípios para a amostra de municípios não consorciados, os quais constam no Quadro 3. No caso de Umuarama, ocorreu uma exceção. Apesar do município não ter participado da pesquisa do SNIS 2010, optou-se em mantê-lo na amostra, pois possui a maior população dentro da respectiva região metropolitana, além de ser a sede desta. 
Quadro 3 - Amostra do grupo de municípios não consorciados

\begin{tabular}{|l|l|}
\hline \multicolumn{1}{|c|}{ Região Metropolitana } & \multicolumn{1}{c|}{ Municípios Selecionados } \\
\hline Região Metropolitana de Londrina (RMLO) & $\begin{array}{l}\text { Assai, Arapongas, Londrina, Primeiro } \\
\text { de Maio, Rolândia e Sabáudia. }\end{array}$ \\
\hline Região Metropolitana de Maringá (RMM) & Astorga, Lobato, Maringá e Santa Fé. \\
\hline Região Metropolitana de Umuarama (RMUM) & $\begin{array}{l}\text { Alto Piquiri, Cruzeiro do Oeste, } \\
\text { Iporã, Nova Olímpia e Umuarama. }\end{array}$ \\
\hline
\end{tabular}

Fonte: Adaptado de Paraná (1998a); Paraná (1998b) e Paraná (2012).

Para a elaboração do questionário, foram considerados aspectos do processo de formação dos consórcios públicos, informações sobre gestão e manejo de resíduos sólidos e alguns indicadores.

Foram elaborados dois modelos de questionários, um para o grupo de municípios consorciados, composto por 17 perguntas fechadas, tais como: motivo de participação; tempo para integrar o consórcio; se havia o interesse em ampliar o objeto do consórcio (coleta, transporte e outros); se havia coleta seletiva e coleta de resíduos especiais no município; se o município estava discutindo alternativas para a implantação de mecanismos de logística reversa; se havia alguma central de triagem e/ou usina de reciclagem no município; a situação das despesas com RSU e a suficiência financeira do sistema do município pós consórcio; e duas perguntas abertas referentes às vantagens e às dificuldades enfrentadas pelo município na participação do Consórcio.

Para o grupo de municípios não consorciados, o questionário foi composto por dez perguntas fechadas, tais como: se havia interesse do município em participar de um consórcio público de RSU; motivo(s) do município ainda não estar consorciado; conhecimento sobre os instrumentos legais exigidos para a formação de consórcios públicos; se havia coleta seletiva e coleta de resíduos especiais no município; se o município estava discutindo alternativas para a implantação de mecanismos de logística reversa; se havia alguma central de triagem e/ou usina de reciclagem no município; onde os resíduos coletados estavam sendo dispostos; e duas perguntas abertas referentes às vantagens que o município teria caso participasse de um Consórcio 
Público e as dificuldades enfrentadas pelo município para participar de um consórcio público.

Quanto à seleção dos entrevistados do grupo dos municípios consorciados, adotou-se a lista de representantes do Consórcio. No caso do grupo dos municípios não consorciados, os entrevistados foram profissionais da área de resíduos sólidos indicados pelas Secretarias responsáveis pelo setor de resíduos sólidos no município. Os questionários foram aplicados pessoalmente quando possível e encaminhados por e-mail após contato prévio por telefone, momento em que se expôs o objetivo da pesquisa, a qual foi realizada nos meses de setembro e outubro de 2013. 


\section{Resultados e discussão}

\section{1 Levantamento dos Consórcios de Resíduos Sólidos}

Conforme mencionado anteriormente, para a identificação e quantificação dos consórcios públicos de resíduos sólidos efetivos no Brasil, a pesquisa baseou-se no levantamento realizado pela CEF em 2011 (BATISTA, 2011a) e no SNIS: diagnóstico do manejo de resíduos sólidos urbanos-2010 (BRASIL, 2012).

No entanto, essas bases de dados apresentaram algumas inconsistências. Por exemplo, no levantamento da Caixa (BATISTA, 2011 a) observou-se que o CONRESOL não estava no universo da pesquisa. No caso das informações do SNIS (BRASIL, 2012), a partir da análise dos dados apresentados para a Região Sul, constatou-se que o número de consórcios específicos, totalmente regulamentados e atuantes na área de resíduos sólidos, é menor. A verificação foi feita por meio de pesquisa on line e contatos telefônicos. No caso do Paraná, o SNIS apresenta oito consórcios, quando, de acordo com o Plano de Regionalização (PARANÁ, 2013), existem cinco consórcios intermunicipais para resíduos, sendo: quatro Consórcios Intermunicipais para aterro sanitário - CIAS Curiúva, CIAS Pontal do Paraná, CIAS Japira e CIAS Paranacity, com compartilhamento de aterro sanitário, e o CONRESOL.

Segundo Batista (2011a), das 409 experiências de Consórcios Públicos Intermunicipais distribuídos pelo Brasil, 48,17\% abrangem a área de saúde; 41,08\% contemplam outros objetos, tais como: desenvolvimento socioeconômico, segurança alimentar e infraestrutura; $7,82 \%$ consórcios têm como objeto a área de meio ambiente, recursos hídricos e saneamento básico; e para meio ambiente e resíduos sólidos constam menos de 3\% das experiências identificadas.

As informações contidas no SNIS (BRASIL, 2012) apontam para 80 Consórcios Intermunicipais que contemplam como objeto a gestão ou a prestação de serviços de manejo de resíduos sólidos, distribuídos conforme o Gráfico 1.

Gráfico 1. Distribuição de Consórcios Públicos por Região

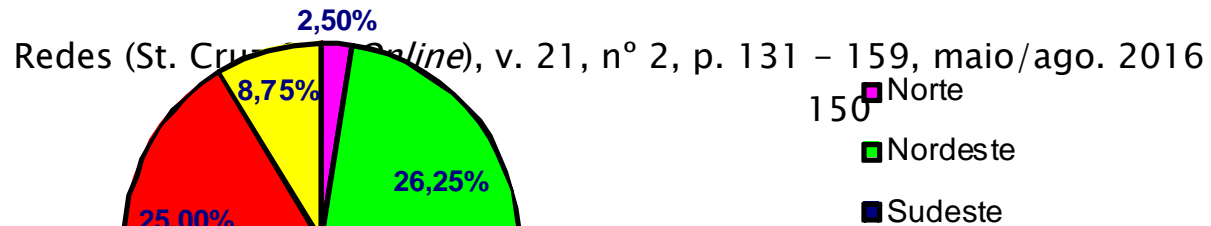


Fonte: Adaptado de Brasil (2012).

A pesquisa realizada em 2013 considerou os dados do SNIS 2010 (BRASIL, 2012), uma vez que estes eram os dados disponíveis na época. Para os anos de 2011, 2012 e 2013, a quantidade de consórcios informada pelo SNIS foi respectivamente 81, 130 e 166 (BRASIL, 2015).

Considerando-se a limitação desses levantamentos, conclui-se que há pouca informação sobre o número de consórcios de resíduos sólidos efetivamente estabelecidos no país, onde estão estes consórcios e qual o objeto específico de tais consórcios. Assim, entende-se que a construção de um mapeamento mais preciso desses consórcios públicos seria o primeiro passo para estabelecer a troca de experiências e consequentemente fomentar a implantação de novos consórcios de resíduos no Brasil.

\subsection{Caracterização do CONRESOL e do Grupo de Municípios não consorciados}

Em relação ao contexto do CONRESOL, é pertinente mencionar que, até a década de 1960, a cidade de Curitiba não tinha local específico para a disposição dos resíduos coletados e realizava a disposição em terrenos particulares distantes da sede municipal e não habitados. A partir de 1964, os resíduos passaram a ser dispostos na área denominada Lamenha Pequena, no Município de Almirante Tamandaré, e durante 25 anos a disposição ocorreu neste local. Nesse período, os demais municípios da RMC dispunham seus resíduos em lixões localizados dentro dos próprios territórios. Em 1989, com o 
esgotamento da vida útil do Aterro da Lamenha Pequena, no período de transição para o Aterro de Curitiba, os resíduos passaram a ser dispostos no aterro controlado Barro Preto, em São José dos Pinhais (NASCIMENTO NETO, 2011 ).

No mesmo ano, o Aterro Sanitário de Curitiba, localizado no bairro da Caximba, localizado entre os municípios de Araucária e Fazenda Rio Grande, iniciou sua operação para receber os resíduos de Curitiba e de São José dos Pinhais. Durante a operação do Aterro da Caximba, outros municípios da Região Metropolitana de Curitiba passaram a dispor seus resíduos na Caximba (CONRESOL, 2008).

O projeto inicial do Aterro da Caximba previa 11 anos e 5 meses de vida útil, mas duas obras de ampliações garantiram a operação até 2010, totalizando 21 anos de operação. Cabe mencionar que as ampliações foram realizadas em caráter emergencial em razão do fracasso do Edital para a implantação de outro aterro sanitário. Para o referido Edital, publicado em 2002, houve duas propostas vencedoras, uma da Estre Ambiental no Município de Fazenda Rio Grande, que devido à falta de anuência do município não obteve licença ambiental; e outra pela Cavo Gestão Ambiental no Município de Mandirituba, que também não foi licenciada em decorrência de ação judicial. (NASCIMENTO NETO, 2011).

Após, o consórcio elaborou a proposta do Sistema Integrado de Processamento e Aproveitamento de Resíduos - SIPAR, publicou-se o Edital em 2007, o qual foi interrompido por conta de ações judiciais e, em 17 de outubro de 2013, foi revogado. Assim, desde 2010, a disposição final dos resíduos dos municípios integrantes do CONRESOL ocorre no Centro de Gerenciamento de Resíduos CGR - Iguaçu, aterro sanitário da Estre Ambiental S.A., localizado no Município de Fazenda Rio Grande, o qual iniciou a operação em 2010, com a previsão de 18 anos de vida útil, com capacidade de recebimento de 75.000 toneladas/mês. Além da área da Estre, conforme informação da Gerência do CONRESOL, o aterro da Essencis Soluções Ambientais S/A, localizado na Cidade Industrial, em Curitiba, também está credenciado para receber os resíduos domiciliares do Consórcio.

Os percalços envolvidos nos processos licitatórios do CONRESOL exemplificam como a questão dos resíduos sólidos é complexa, muito 
mais por questões políticas, administrativas e interesses particulares do que por questões técnicas.

A Tabela 1 apresenta os 21 municípios que integram o CONRESOL e mostra o perfil diversificado destes. Alguns totalmente urbanizados, como Curitiba e Pinhais, e outros, pouco urbanizados, como Tijucas do Sul e Quitandinha. Também se nota a variação do Produto Interno Bruto - PIB per capita, que vai de R\$5.869,00/habitante de Piraquara a R\$ 103.778,00/habitante de Araucária, o que reflete a composição heterogênea do consórcio, por meio do qual se viabiliza a disposição adequada para municípios que, sozinhos, não teriam condições técnicas e financeiras de atendimento, e para municípios que não dispõem de áreas, por exemplo, Curitiba e Pinhais.

Acrescente-se o comentário de Ceccon (2009): se cada município do CONRESOL ficasse responsável por seu próprio resíduo, inevitavelmente haveria grande degradação ambiental pela disposição inadequada dos resíduos.

Tabela 1 - Indicadores gerais dos Municípios do Conresol

\begin{tabular}{|c|c|c|c|c|}
\hline Município & $\begin{array}{c}\text { População } \\
\text { Total }\end{array}$ & \% Consórcio & $\begin{array}{l}\text { Grau de } \\
\text { Urb. (\%) }\end{array}$ & $\begin{array}{c}\text { PIB Per } \\
\text { Capita } \\
(\mathrm{R} \$ 1,00)\end{array}$ \\
\hline Agudos do Sul & 8.270 & 0,27 & 34,12 & 8.940 \\
\hline Almirante Tamandaré & 103.245 & 3,40 & 95,82 & 7.012 \\
\hline Araucária & 119.207 & 3,92 & 92,51 & 103.778 \\
\hline Balsa Nova & 11.294 & 0,37 & 60,80 & 25.709 \\
\hline Bocaiúva do Sul & 11.005 & 0,36 & 46,67 & 9.796 \\
\hline $\begin{array}{l}\text { Campina Grande do } \\
\text { Sul }\end{array}$ & 38.756 & 1,28 & 82,44 & 15.091 \\
\hline Campo Largo & 112.486 & 3,70 & 83,80 & 14.585 \\
\hline Campo Magro & 24.836 & 0,82 & 78,68 & 8.402 \\
\hline Colombo & 213.027 & 7,01 & 95,42 & 9.991 \\
\hline Contenda & 15.892 & 0,52 & 58,09 & 10.011 \\
\hline Curitiba & 1.746 .896 & 57,49 & 100,00 & 30.400 \\
\hline Fazenda Rio Grande & 81.687 & 2,69 & 92,96 & 7.575 \\
\hline Mandirituba & 22.235 & 0,73 & 33,37 & 12.422 \\
\hline Piên & 117.166 & 3,86 & 40,25 & 25.007 \\
\hline Pinhais & 11.236 & 0,37 & 100,00 & 38.348 \\
\hline Piraquara & 93.279 & 3,07 & 49,07 & 5.869 \\
\hline Quatro Barras & 19.786 & 0,65 & 90,38 & 30.795 \\
\hline Quintandinha & 4.134 & 0,14 & 28,60 & 8.856 \\
\hline
\end{tabular}




\begin{tabular}{lrrrr} 
São José dos Pinhais & 263.488 & 8,67 & 89,66 & 51.960 \\
Tijucas do Sul & 14.526 & 0,48 & 15,72 & 14.736 \\
Tunas do Paraná & 6.258 & 0,21 & 44,63 & 7.880 \\
\hline Total & 3.038 .709 & 100 & - & -
\end{tabular}

Fonte: Adaptado de IPARDES (2010).

Os municípios do CONRESOL ocupam um território de $8.980 \mathrm{~km}^{2}$, com uma população de mais de três milhões de habitantes, sendo que Curitiba concentra mais de $57 \%$ da população total do Consórcio. Além de Curitiba, também se destacam os municípios de Colombo e Pinhais com alta densidade demográfica.

Convém mencionar que o impacto do crescimento populacional da RMC, nas últimas três décadas, implicou no aumento da geração de resíduos sólidos e a temática - crescimento populacional e aumento de geração de resíduos versus adequação dos aterros sanitários tem sido abordada tanto pela sociedade quanto pelo poder público (PATRíCIO, 2015).

O Gráfico 2 apresenta a quantidade de resíduos dispostos no Aterro Sanitário da ESTRE, em dezembro de 2012, pelos municípios do CONRESOL e destaca Curitiba com, aproximadamente $70 \%$ da disposição de resíduos, seguida por São José dos Pinhais (7,58\%), Colombo $(6,20 \%)$ e Araucária (3,15\%).

Gráfico 2 - Percentual de resíduos depositados no aterro (2012)

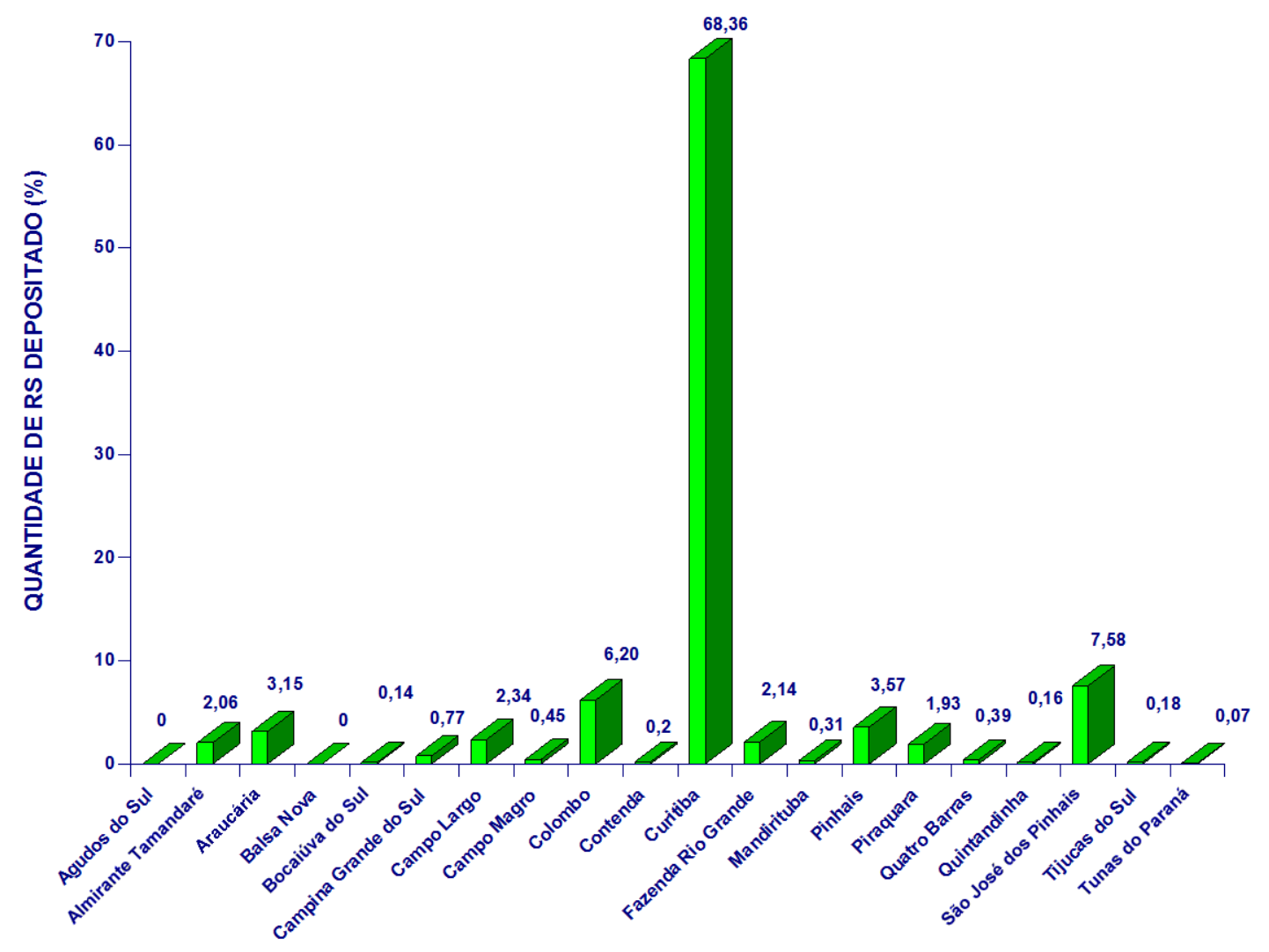


Fonte: Adaptado de CONRESOL (2013).

Em relação ao grupo de municípios não consorciados, conforme a Tabela 2, dos 15 municípios não consorciados e selecionados para a pesquisa, 4 deles são de grande porte, com mais de 100 mil habitantes: Arapongas, Londrina, Maringá e Umuarama; 1 município de médio porte - Rolândia; e os demais municípios de pequeno porte. 
Tabela 2. Indicadores gerais dos municípios não consorciados

\begin{tabular}{lr|r|r|r}
\hline \multicolumn{1}{c|}{ Município } & População & $\begin{array}{c}\text { Grau de } \\
\text { Urbanização }\end{array}$ & PIB Per Capita & $\begin{array}{c}\text { Massa } \\
\text { Coletada Per } \\
\text { Capita I }\end{array}$ \\
\hline Alto Piquiri & 10.179 & 82,29 & 14.094 & 0,93 \\
Arapongas & 104.150 & 97,79 & 22.207 & 0,84 \\
Assai & 16.354 & 83,08 & 17.202 & 0,59 \\
Astorga & 24.698 & 91,34 & 14.546 & 0,63 \\
Cruzeiro do Oeste & 20.416 & 86,54 & 16.348 & 0,48 \\
Iporã & 14.981 & 78,61 & 13.875 & 0,72 \\
Lobato & 4.401 & 93,27 & 28.714 & 0,30 \\
Londrina & 506.701 & 97,40 & 21.071 & ND \\
Maringá & 357.077 & 98,20 & 26.810 & 1,48 \\
Nova Olímpia & 5.503 & 85,14 & 8.014 & 0,88 \\
Primeiro de Maio & 10.832 & 93,09 & 15.057 & - \\
Rolândia & 57.862 & 94,62 & 23.124 & 0,56 \\
Sabáudia & 6.096 & 83,61 & 24.228 & - \\
Santa Fé & 10.432 & 88,50 & 15.451 & - \\
Umuarama & 100.676 & 92,83 & 15.365 & - \\
\hline
\end{tabular}

Fonte: Adaptado de IPARDES (2010) e (SINIR, 2010).

Nota!: Massa (resíduo domiciliar e resíduo público) coletada per capita em relação à população urbana (SINIR, 2010)

Os municípios apresentam grau de urbanização alto, com média acima da média do Estado, que é de $85,33 \%$. A variação do PIB per capita é de $R \$ 8.014,00 /$ habitante de Nova Olímpia a $R \$ 28.714,00 /$ habitante de Lobato.

Em relação à massa coletada, percebe-se uma variação considerável, de 0,56 kg/hab./dia de Rolândia a 1,48 kg/hab./dia de Maringá, sendo a média apontada para o Paraná pelo SNIS igual a 0,9 $\mathrm{kg} / \mathrm{hab}$./dia.

Quanto ao Plano de Gestão Integrada de Resíduos Sólidos - PGIRS, condição para os municípios acessarem recursos da União destinados a empreendimentos e serviços relacionados à limpeza urbana e ao manejo de resíduos sólidos, destes municípios, apenas Londrina possui Plano concluído.

Considerando-se que o planejamento é fundamental para a adequada gestão dos resíduos sólidos, assim como para outras áreas, o fato de um município ainda não ter elaborado seu Plano dentro do prazo inicial previsto pela Lei n. 12.305/2010 (ano de 2014), o qual foi 
prorrogado para dezembro de 2015 , demonstra o grau de dificuldade dos municípios em atender às exigências postas pelo marco regulatório da prestação dos serviços de manejo de resíduos sólidos.

É pertinente comentar que até municípios onde a questão de resíduos sólidos está mais avançada, o conteúdo do PGIRS nem sempre atende ao inteiro teor previsto na PNRS. Esse fato foi evidenciado por Silva (2015b) em um estudo comparativo de três metrópoles brasileiras - Curitiba, Porto Alegre e Salvador. Ainda, segundo Silva (2015a), para a elaboração dos referidos planos, os municípios devem considerar os fatores institucionais, sociais, financeiros, econômicos, técnicos e ambientais.

Quanto ao levantamento de indicadores de resíduos sólidos pelo SINIR, o qual se baseia no SNIS (BRASIL, 2012), estes foram feitos com o objetivo de permitir uma comparação entre os dois grupos de municípios, até mesmo para atestar as vantagens do consórcio por meio de indicadores. Para esta pesquisa, com base nos resultados das médias calculadas para os indicadores selecionados, observou-se que o desempenho do grupo do CONRESOL não apresentou superioridade, quando comparado ao grupo de municípios não consorciados.

Todavia, um banco de dados desses indicadores é útil por compor uma série histórica e permitem, no futuro, correlações com ações de gestão e gerenciamento de resíduos dos municípios para fins de planejamento do setor.

\subsection{Resultados da pesquisa de campo}

Os principais resultados da pesquisa de campo estão apresentados primeiramente para o grupo de municípios consorciados e depois para o grupo de municípios não consorciados.

Dos 21 municípios que integram o CONRESOL 13 participaram da pesquisa $(61,9 \%)$ : Almirante Tamandaré, Araucária, Campina Grande do Sul, Campo Largo, Campo Magro, Contenda, Curitiba, Mandirituba, Piên, Pinhais, Piraquara, Quatro Barras e São José dos Pinhais, os quais representam aproximadamente $88 \%$ dos resíduos dispostos pelo Consórcio.

Para os 13 questionários aplicados, a pesquisa indicou para esse grupo que a maioria dos municípios, 55\% dos entrevistados, optou em 
consorciar-se por iniciativa própria; $27 \%$ por outros motivos, tais como: dispor adequadamente os resíduos gerados e falta de alternativa; $18 \%$ afirmaram ter recebido convite de outro município e nenhum mencionou apoio de esferas governamentais.

Sobre o apontamento da inexistência de apoio governamental, pode-se comentar que, na época da formação do Consórcio, a Coordenação da Região Metropolitana de Curitiba - COMEC já havia sido criada há 27 anos e a instituição foi responsável por estudos do sistema de gestão de resíduos da RMC, o que fortaleceu a discussão técnica nessa área. Assim, o incentivo da esfera governamental não ocorreu de forma direta. Havia um cenário favorável à formação do CONRESOL em função dos avanços nas discussões sobre a gestão dos resíduos no âmbito regional.

A pesquisa indicou que a iniciativa do município foi fundamental para o processo. O consórcio não funciona de forma imposta, viabilizase por meio de um processo de negociação entre os municípios. Essa negociação enfrenta diversos impasses, principalmente devido a diferenças políticas, partidárias, demais interesses e conflitos que possam existir, em especial, a definição de área para a disposição final dos resíduos.

Em relação ao tempo para ingresso no CONRESOL, 73\% levaram menos de um ano, $27 \%$, de um a dois anos e nenhum mais de dois anos, sendo que $80 \%$ dos municípios afirmaram que o tempo de constituição do consórcio é longo em função do trâmite burocrático. Porém, considerando que a maioria levou menos de um ano para ingressar no CONRESOL, pode-se constatar que nesse aspecto a burocracia não se mostrou um empecilho.

Assim, quanto ao ritual jurídico para a implantação do consórcio público, pode-se inferir que, após a negociação entre os municípios, o prazo do trâmite burocrático não representa um entrave, portanto, pode-se afirmar que o processo previsto para a formalização dos consórcios públicos representa muito mais segurança jurídica do que morosidade.

Ainda com relação ao ingresso no Consórcio, 20\% afirmaram que a negociação com os demais municípios é o que mais impacta neste aspecto, ou seja, compatibilizar demandas de cada município, gerenciar 
conflitos políticos e estabelecer local para a disposição final de resíduos, com a anuência da população local, constitui uma tarefa complexa.

Sobre o resultado prático com a participação em Consórcio, 64\% indicaram a disposição final adequada e $36 \%$, o custo com os serviços. Esse custo significa o aumento de recursos para dispor adequadamente e não reflete a redução de custo por economia de escala.

Quando essa questão foi elaborada, considerou-se que o município desembolsa menos recursos para a disposição adequada sob a forma consorciada do que sob a forma isolada, porém, neste caso, os municípios antes de se consorciarem não realizavam a disposição adequada, portanto, desembolsavam menos recursos para $o$ gerenciamento dos resíduos e, assim, apontaram que, ao se consorciarem, houve aumento dos custos. De qualquer modo, sob a forma consorciada, o custo é acessível para esses municípios realizarem a disposição final adequada, do contrário, eles teriam resolvido essa questão sozinhos e não teriam aderido ao consorciamento.

Acrescente-se que a maioria das respostas sobre o resultado prático com a participação em Consórcio aponta a disposição final (64\%), uma vez que as atribuições do CONRESOL são somente para a disposição e tratamento dos resíduos.

Para a informação sobre a diversificação da prestação de serviços por meio do consórcio, $46 \%$ responderam que não gostariam que o objeto do Consórcio fosse ampliado e $54 \%$ responderam que gostariam. Esse dado é relevante quando se faz referência à Lei 12.305/2010, que recomenda o consórcio para outras etapas do gerenciamento de resíduos. Também reflete um resultado equilibrado nas posições contrárias e reforça a situação que ocorreu no passado, momento em que, conforme Nascimento Neto (2011), a intenção inicial do Consórcio era abranger outras etapas do gerenciamento dos RSUs, como coleta e transporte, mas, em função da heterogeneidade dos serviços prestados em cada município, isso não foi consensual.

Pelo ranking das vantagens apresentadas nos questionários, os pontos mais fortes de um Consórcio de resíduos sólidos são: a viabilidade da disposição adequada; o suporte técnico, administrativo e jurídico proporcionado pela equipe disponibilizada; a redução de custos na disposição adequada; a praticidade e conveniência; e o ganho de escala, o que está de acordo com Brasil (2010c) e Chieco (2011). 
Em relação às dificuldades elencadas, dos 13 municípios consorciados que participaram da pesquisa, seis deles apontaram alguma dificuldade, a saber: solução tecnológica de comum acordo, contrato de rateio anual com burocracia que atrasa repasses e centralização das decisões em Curitiba; entraves judiciais e transição política; acesso ao Aterro; dificuldade de ordem financeira e para implantar novas tecnologias de valorização, tratamento e disposição final dos resíduos; burocracia e impasses políticos; custos e planejamento integrado por região.

A questão financeira perpassa todas as dificuldades citadas e, sobre a transição e impasses políticos, percebe-se, na história do CONRESOL, que, quando a Prefeitura de Curitiba é de um partido político e o Governo do Estado é de outro partido, a execução das ações torna-se mais difícil. Um exemplo seria o ocorrido em junho de 2008, quando protocolou-se o pedido de licenciamento prévio para a área do Município de Mandirituba, área prioritária para o empreendimento do SIPAR, e o Instituto Ambiental do Paraná - IAP expediu a licença somente em outubro de 2010, quando a licitação do CONRESOL para a implantação do SIPAR já estava paralisada. Também se pode citar que, em 2008, houve a edição da Lei Municipal que proibiu o recebimento de resíduos de outros municípios em Mandirituba.

Em relação ao aspecto econômico, para $73 \%$ dos entrevistados, as despesas com resíduos aumentaram e, para $27 \%$, não houve mudança, enquanto a despesa per capta aumentou para $82 \%$ e, para $18 \%$, não houve mudança. $O$ aumento dos custos é resultado da disposição final adequada, ou seja, quando a questão ambiental passa a atender a legislação é necessário um investimento inicial. Já os municípios que informaram que não houve mudança não possuíam informações disponíveis sobre os custos do gerenciamento dos resíduos anterior à data de constituição do consórcio, o que pode causar uma falsa percepção de que os custos se mantiveram.

Destaque-se que o investimento inicial se refere aos custos apropriados para a implantação e operação de um aterro sanitário. A implantação compreende infraestrutura geral (projetos, mobilização, canteiro, topografia, cercamento e instalações elétricas); células de disposição (terraplanagem, drenagem, impermeabilização de base); sistema de coleta e tratamento de percolados e gases; instalações de 
apoio (portaria, guarita, laboratório, administração). A operação envolve custos anuais de rotina de um aterro sanitário, bem como procedimentos de encerramento e pós-encerramento, engloba disposição de resíduos (preparo, espalhamento, compactação, cobertura), sistema de drenagem e tratamento de percolados e gases (drenos, flare e outros), monitoramento ambiental, equipe de operação e administração (PARANÁ, 2013).

Dos 15 municípios não consorciados e pertencentes às regiões metropolitanas de: RMM, RMLO e RMUM, que foram selecionados para a pesquisa, 11 responderam ao questionário (73,33\%): Alto Piquiri, Assaí, Astorga, Cruzeiro do Oeste, Londrina, Maringá, Primeiro de Maio, Rolândia, Sabáudia, Santa Fé e Umuarama.

Para esse grupo, dos 11 questionários aplicados, a pesquisa apontou que a maioria, $80 \%$ dos entrevistados, gostaria de integrar um Consórcio Público de Resíduos Sólidos, e que o motivo disso ainda não ter acontecido, segundo $55 \%$ dos pesquisados, é em virtude da negociação com demais municípios; $36 \%$ atribuem o fato a outros motivos, tais como: possuir local adequado para a disposição final, divergências políticas e custo inicial; enquanto para $9 \%$ o fator atribuído é o trâmite burocrático.

É pertinente comentar que, para o grupo do CONRESOL, o fator negociação com os demais municípios para a formação do Consórcio representou $20 \%$ contra $80 \%$ de trâmite burocrático, enquanto para o grupo de municípios não consorciados a negociação representa mais de $50 \%$ das razões destes municípios não serem consorciados. Tal diferença pode se explicar pelo maior tempo de constituição da região metropolitana de Curitiba, desde 1973 e, por conseguinte, a existência de um órgão de planejamento metropolitano mais consolidado do que nas regiões metropolitanas criadas posteriormente e que propiciou o avanço nas discussões sobre resíduos sólidos por meio do Programa de Saneamento Ambiental - PROSAM.

Sobre o conhecimento do trâmite jurídico necessário para a formação de Consórcios Públicos, $45 \%$ afirmaram não conhecer os instrumentos legais exigidos e $55 \%$ responderam que conhecem. Também se identificou que $100 \%$ dos entrevistados consideram que a participação do município em um Consórcio dessa espécie é importante. Assim, considerando a importância atribuída a este arranjo institucional 
e o percentual que desconhece os procedimentos necessários para a formação de um consórcio público, fica evidente a necessidade de ações de capacitação e divulgação nessa área.

Quanto à comparação sobre o manejo de resíduos sólidos entre o grupo de municípios consorciados e não consorciados, nas categorias coleta seletiva, coleta de resíduos especiais, discussão sobre mecanismos de logística reversa, existência de centrais de triagem e separação de resíduo orgânico, não há disparidade nos resultados. Os resultados do grupo consorciado não são significativamente melhores porque o consórcio não influencia diretamente estes indicadores, uma vez que o escopo do CONRESOL abrange somente tratamento e disposição final dos resíduos sólidos.

No grupo dos municípios não consorciados, $70 \%$ dispõem seus resíduos em Aterro Sanitário, $20 \%$ em Aterro Controlado e $10 \%$ em lixões. Assim, considerando que $30 \%$ desses municípios estão dispondo os resíduos de forma inadequada e que a maioria deles (80\%) gostaria de integrar um Consórcio Público de Resíduos Sólidos, é oportuno que existam esforços para fortalecer a proposta de consórcios públicos no Paraná.

Entre as vantagens apresentadas nos questionários, destaca-se a viabilidade técnica e financeira da disposição adequada (54,55\%), a redução de custos $(36,36 \%)$ e a melhoria na coleta seletiva (36,36\%). As questões da disposição adequada e de custos também foram as vantagens mais citadas pelo grupo dos municípios consorciados, e a questão do custo, neste caso, significa a viabilidade de disposição adequada.

Quanto às dificuldades apontadas, pode-se citar:

- Falta de recursos e estrutura; necessidade de alocação de valor inicial alto para viabilizar o consórcio.

- Falta de apoio governamental na esfera estadual e federal; carência de recursos para projetos e sistemas de tratamento de resíduos.

- Encarecimento do transporte do resíduo até o local definido. Quando o município gasta pouco para transportar o resíduo até um local dentro do seu território, ao integrar um consórcio é muito provável que o mesmo tenha que despender um valor mais alto com o transporte até o local definido pelo grupo consorciado. 
- Ausência de cooperação entre os municípios; conflitos de interesses; dificuldade na definição das prioridades de cada município. Cada município possui uma realidade diferenciada. As dificuldades são diferentes pela natureza e dimensão. Às vezes, o problema é maior na área de saúde ou educação, sugerindo que a questão dos resíduos sólidos não é prioridade; conflitos políticos e divergências partidárias; portanto, há falta de interesse em soluções consorciadas.

- Burocracia e desconhecimento das prefeituras e Câmaras; falta de intercâmbio entre técnicos para troca de experiência.

- Passivo ambiental.

- Resistência da população para receber "lixo" de outros municípios.

A questão do passivo ambiental foi comentada em função da desconfiança que a sociedade tem sobre a operação adequada de um aterro sanitário. Existe a tendência das pessoas pensarem que um aterro sanitário, com o passar do tempo, transformar-se-á em um lixão e, mesmo tratando-se de aterro sanitário, existe o medo da população pelos impactos ambientais que este possa causar. Para as áreas selecionadas para a construção de aterros sanitários pressupõe-se que se tornarão passivo ambiental. Nesse aspecto, é importante que os municípios esclareçam essas questões com a população, por meio de divulgação, audiências, ações de educação ambiental e, principalmente, que a definição de área seja com base em critérios técnicos e não políticos.

Pode-se afirmar que as questões econômicas e políticas partidárias representam fatores determinantes para o entrave na formação de novos consórcios públicos de resíduos sólidos.

Em relação aos custos, é pertinente comentar que inicialmente o município despenderá um valor maior, que, ao longo do tempo, será compensado em função da economia de escala. A maior vantagem sob a forma consorciada é a viabilização da disposição adequada. Acrescentese que os municípios consorciados têm prioridade na obtenção de recursos financeiros, conforme prevê a Lei n. 12.305/2010.

Após a resolução da disposição final adequada, o consórcio também pode ser uma boa alternativa para o desenvolvimento de outros projetos, programas de educação ambiental, reciclagem, compostagem, conforme as particularidades de cada situação regional. 
Acrescente-se que, se por um lado um aterro que atenda uma população maior possa ter uma diminuição de vida útil, em decorrência de um maior número de municípios que passam a realizar a disposição final no local, o compartilhamento de custos pode melhorar os processos de reutilização e reciclagem, bem como, viabilizar o investimento em outras tecnologias de tratamento.

No grupo dos municípios não consorciados, revelou-se que mais da metade dos municípios não conhece os instrumentos legais de um consórcio público. Isso indica a necessidade de orientação e capacitação sobre o assunto, o que pode ser realizado via esfera federal por meio de um plano intenso e abrangente para atender esta demanda.

A pesquisa indicou para o grupo de municípios consorciados o aumento das despesas com resíduos. Esse incremento é resultado da disposição adequada, ou seja, era mais barato dispor inadequadamente, porém, os custos dessa disposição inadequada se perpetuam no tempo pelos impactos ambientais, sociais e de saúde pública que causam, tornando a contabilização desses passivos ambientais algo muito complexo.

A pesquisa demonstrou a importância do consórcio público de resíduos sólidos para a viabilização da disposição adequada ao evidenciar o CONRESOL, que representa um terço da população do Paraná com disposição adequada. Em contrapartida, no grupo de municípios não consorciados, 30\% realizam disposição inadequada e, mesmo aqueles que dispõem seus resíduos em aterros sanitários, devem preocupar-se com a vida útil desses aterros, considerando a tendência crescente na geração de resíduos e as exigências para licenciamento ambiental de novas áreas.

Quanto ao aumento na geração de resíduos sólidos, destaque-se a importância da implantação de programas de educação ambiental contínua e programas de comunicação e mobilização social como forma de estímulo à institucionalização do conceito de sustentabilidade por parte da população, para que esta busque modificar hábitos de consumo e assuma suas responsabilidades, especialmente, em relação à correta separação e destinação dos resíduos recicláveis.

Acrescente-se que, o Consórcio Público também pode fortalecer projetos de reciclagem e inclusão social, os quais, segundo Silva (2015), terão mais chances de efetiva implementação por meio do trabalho em 
rede social (prefeituras, secretarias municipais, instituições públicas, privadas e não governamentais, catadores, carrinheiros de materiais recicláveis e cooperados), a exemplo do Projeto ECOCIDADÃO, implementado pela Prefeitura de Curitiba.

\section{Considerações finais}

A formação de consórcios públicos de resíduos sólidos é influenciada por questões político partidárias, conflitos e interesses municipais, e requer análises técnicas e econômicas que demonstrem a viabilidade dos mesmos.

No caso do CONRESOL, a COMEC desempenhou papel importante para a consolidação do consórcio, pela disponibilização de informações técnicas e estudos decorrentes de análise de planejamento e desenvolvimento regional.

Assim, para os demais municípios do Paraná, recomendam-se instituições com atuações regionais que possam desempenhar o papel de fortalecer a proposta de consórcios públicos. Tratando-se das demais regiões metropolitanas do Estado as Coordenações Regionais Metropolitanas podem assumir essa função. Independente da natureza das instituições, é vital que as mesmas estejam bem estruturadas e preparadas para atuar na formação dos consórcios públicos.

A pesquisa indicou que a questão econômica é um dos aspectos preponderantes na constituição dos consórcios públicos de resíduos. Uma alternativa para minimizar essa questão é incentivar a implantação de consórcios de resíduos por meio de subsídios financeiros, para viabilizar projetos e investimentos iniciais.

Em relação ao objeto do consórcio de resíduos, embora a Lei o recomende para várias etapas do gerenciamento, quando os municípios apresentam sistemas heterogêneos, a alternativa mais viável é implantálo, inicialmente, para a disposição final e, depois de consolidada a disposição adequada, avaliar outras atividades. No caso de municípios pequenos em que exista a possibilidade de compartilhar o caminhão de coleta, por exemplo, é apropriado contemplar a coleta no objeto do consórcio. Para programas de educação ambiental, comunicação social e mobilização social, também é interessante otimizar recursos e padronizar materiais institucionais do consórcio. Enfim, é recomendável 
analisar cada situação para considerar as particularidades de cada proposta.

Quanto à qualificação do quadro funcional dos municípios, é preciso que o governo promova capacitação técnica contínua. No primeiro momento, em relação à legislação aplicável, trâmite jurídico para a constituição de consórcios públicos, administração de conflitos e técnicas de negociação, por exemplo. Sugere-se a criação de uma instituição regional com atribuição para esse assunto, a qual poderia diagnosticar as necessidades específicas e, a partir desse diagnóstico, sugerir soluções para cada consórcio a se constituir.

E, por fim, é imprescindível a vontade e iniciativa dos municípios para a formação de um Consórcio Público. Portanto, cabe aos mesmos os contatos com municípios próximos para o início da articulação intermunicipal, indicar possíveis áreas para definição de aterros sanitários e buscar capacitação na área.

Dessa forma, as recomendações para a formação de novos consórcios públicos de resíduos sólidos no Paraná também são aplicáveis em outros estados, uma vez que o Consórcio Público é um modelo de gestão adequado e viável para que os municípios possam superar os desafios de gestão e manejo dos RSUs. Acrescente-se que essa alternativa de arranjo institucional, na medida em que viabiliza a disposição final adequada, contribui para a minimização de impactos ambientais, melhoria da saúde e qualidade de vida da população.

\section{REFERÊNCIAS}

ASSOCIAÇÃO BRASILEIRA DE EMPRESAS DE LIMPEZA PÚBLICA E RESÍDUOS ESPECIAIS (ABRELPE). Panorama dos Resíduos Sólidos no Brasil 2012.

Disponível em $<$ http://www.abrelpe.org.br/panorama_edicoes.cfm $>$. Acesso em 23 nov. 2013.

ASSOCIAÇÃO BRASILEIRA DE EMPRESAS DE LIMPEZA PÚBLICA E RESÍDUOS ESPECIAIS (ABRELPE). Panorama dos Resíduos Sólidos no Brasil 2014. Disponível em $<$ http://www.abrelpe.org.br/panorama_edicoes.cfm $>$. Acesso em 23 mai. 2016. 
BATISTA, Sinoel. As possibilidades de implementação do consórcio público. Brasília: Caixa Econômica Federal, 2011 a.

BATISTA, Sinoel. O papel dos dirigentes municipais e regionais na criação e gestão dos consórcios públicos. Brasília: Caixa Econômica Federal, $2011 \mathrm{~b}$.

BATISTA, Sinoel. O papel dos prefeitos e das prefeitas na criação e na gestão dos consórcios públicos. Brasília: Caixa Econômica Federal, $2011 \mathrm{c}$.

BRASIL. Lei Complementar 14, de 8 de junho de 1973. Estabelece as regiões metropolitanas de São Paulo, Belo Horizonte, Porto Alegre, Recife, Salvador, Curitiba, Belém e Fortaleza. Diário Oficial [da] República Federativa do Brasil, Brasília, DF, 11 jun. 1973. Disponível em: <http://www.planalto.gov.br/ccivil_03/leis/LCP/Lcp14.htm>. Acesso em: 24 jun. 2013.

BRASIL. Lei 6.938, de 31 de agosto de 1981. Dispõe sobre a Política Nacional do Meio Ambiente. Diário Oficial [da] República Federativa do Brasil, Brasília, DF, 2 set. 1981. Disponível em:

<http:// http://www.planalto.gov.br/ccivil_03/leis/16938.htm>. Acesso em: 23 mar. 2013.

BRASIL. Lei 9.433, de 8 de janeiro de 1997. Institui a Política Nacional de Recursos Hídricos, cria o Sistema Nacional de Gerenciamento de Recursos Hídricos, regulamenta o inciso XIX do art. 21 da Constituição Federal, e altera o art. $1^{\circ}$ da Lei $n^{\circ} 8.001$, de 13 de março de 1990, que modificou a Lei $n^{\circ} 7.990$, de 28 de dezembro de 1989. Diário Oficial [da] República Federativa do Brasil, Brasília, DF, 9 jan. 1997. Disponível em:

<http://www.planalto.gov.br/ccivil_03/leis/19605.htm>. Acesso em: 23 mar.2013.

BRASIL. Lei 9.605, de 12 de fevereiro de 1998. Dispõe as sanções penais e administrativas derivadas de condutas e atividades lesivas ao meio 
ambiente, e dá outras providências. Diário Oficial [da] República Federativa do Brasil, Brasília, DF, 13 fev. 1998. Disponível em: <http://www.planalto.gov.br/ccivil_03/leis/19605.htm>. Acesso em: 23 mar.2013.

BRASIL. Lei 11.107, de 6 de abril de 2005. Dispõe sobre normas gerais de contratação de consórcios públicos e dá outras providências. Diário Oficial [da] República Federativa do Brasil, Brasília, DF, 7 abr. 2005. Disponível em: <http://www.planalto.gov.br/ccivil_03/_ato20042006/2005/lei//1 1107.htm>. Acesso em: 15 abr. 2013.

BRASIL. Lei 11.445 , de 5 de janeiro de 2007. Estabelece diretrizes nacionais para o saneamento básico. Diário Oficial [da] República Federativa do Brasil, Brasília, DF, 8 jan. 2007. Disponível em: $<$ www.planalto.gov.br/ccivil_03/_ato20072010/2007/lei/l1 1445.htm>. Acesso em: 24 mar. 2013.

BRASIL. Lei 12.305, de 2 de agosto de 2010a. Institui a Política Nacional de Resíduos Sólidos; altera a Lei no 9.605, de 12 de fevereiro de 1998; e dá outras providências. Diário Oficial [da] República Federativa do Brasil, Brasília, DF, 3 ago. 2010 Disponível em: <http://www.planalto.gov.br/ccivil_03/_ato20072010/2010/lei//12305.htm>. Acesso em: 24 mar. 2013.

BRASIL. Ministério do Meio Ambiente. Manual para Elaboração de Gestão Integrada de Resíduos Sólidos dos Consórcios Públicos. Brasília, 2010b. Disponível em <http:// www.sinir.gov.br/web/guest/publicacoes>. Acesso em 23 maio 2013.

BRASIL. Ministério do Meio Ambiente. Manual para Implantação de Compostagem e Coleta Seletiva no Âmbito de Consórcios Públicos. Brasília, 2010c. Disponível em <http:// www.sinir.gov.br/web/guest/publicacoes>. Acesso em 23 maio 2013.

BRASIL. Secretaria Nacional de Saneamento Ambiental. Sistema Nacional de Informações sobre Saneamento: diagnóstico do manejo de resíduos sólidos urbanos - 2010. Brasília: MCIDADES. SNSA, 2012. Disponível em: 
$<$ www.snis.gov.br/PaginaCarrega.php?EWRErterterTERTer $=93>$. Acesso em: 26 fev. 2013.

BRASIL. Secretaria Nacional de Saneamento Ambiental. Sistema Nacional de Informações sobre Saneamento: diagnóstico do manejo de resíduos sólidos urbanos - 2014. Brasília: MCIDADES. SNSA, 2016. Disponível em: <http://www.snis.gov.br/diagnostico-residuos-solidos/diagnostico-rs2014 >. Acesso em: 24 mai. 2016.

CALDERAN, Thanabi Bellenzier; MAZZARINO, Jane; KONRAD, Odorico. Consórcios intermunicipais para a gestão de resíduos sólidos domésticos e como elemento de desenvolvimento regional sustentável. Revista de Direito Ambiental. São Paulo, n. 66, p. 317-333, abr./jun. 2012.

CECCON, Naiara Pereira. Arranjo Institucional do Consorcio Intermunicipal da RMC de Curitiba para Gestão de Resíduos Sólidos Urbanos: Desafios e Oportunidades. 169 f. Dissertação (Programa de Pós-Graduação em Gestão Urbana - Mestrado e Doutorado) - Pontifícia Universidade Católica do Paraná, Curitiba. 2009.

CHIECO, Thiago Alves. O papel dos consórcios públicos no setor de saneamento básico à luz da Lei 11.445/2007 e do decreto 7.217/2010. In: OLIVEIRA, José Roberto Pimenta; Pozzo, Augusto Neves Dal (Coord.). Estudos sobre o marco regulatório de saneamento básico no Brasil. Belo Horizonte: Fórum, p. 155-201, 2011.

CONSÓRCIO INTERMUNICIPAL PARA A GESTÃO DE RESÍDUOS SÓLIDOS (CONRESOL). Planilha de Controle de Rateio. Curitiba: CONRESOL, 2013.

CONSÓRCIO INTERMUNICIPAL PARA A GESTÃO DE RESÍDUOS SÓLIDOS (CONRESOL). Plano de Gerenciamento do Tratamento e Destinação de Resíduos Sólidos. Curitiba: CONRESOL, 2008. Disponível em< http://www.curitiba.pr.gov.br/conteudo/smma-consorciointermunicipal-para-gestao-dos-residuos-solidos-urbanos/132> Acesso em: 30 abr. 2013. 
INSTITUTO PARANAENSE DE DESENVOLVIMENTO ECONÔMICO E SOCIAL (IPARDES). Perfil dos Municípios, 2010. Disponível em: $<$ http://www.ipardes.pr.gov.br/index.php?pg_conteudo=1\&cod_conteu do=30> Acesso em: 05 jul. 2013.

NASCIMENTO NETO, Paulo. Arranjos Intermunicipais de Gestão de Resíduos Sólidos Urbanos: Estudo de Caso nas Regiões Metropolitanas de Curitiba, Belo Horizonte e Salvador. 340 f. Dissertação (Programa de Pós-Graduação em Gestão Urbana - Mestrado e Doutorado) - Pontifícia Universidade Católica do Paraná, Curitiba. 2011.

PARANÁ. Lei Complementar 81, de 17 de junho de 1998a. Institui a Região Metropolitana de Londrina, constituída pelos municípios que especifica. Alterada pela Lei Complementar 144, de 11 de abril de 2012 - inclui os municípios de Sabáudia, Jaguapitã e Pitangueiras na Região Metropolitana de Londrina. Diário Oficial [do] Estado do Paraná, Curitiba, PR, 11 abr. 2012. Disponível em: < http://www.legislacao.pr.gov.br/legislacao/pesquisarAto>. Acesso em: 24 jun. 2013.

PARANÁ. Lei Complementar 83, de 17 de julho de 1998b. Institui a Região Metropolitana de Maringá, constituída pelos municípios que especifica. Alterada pela Lei Complementar 145, de 24 de abril de 2012 - inclui o município de Nova Esperança na Região Metropolitana de Maringá. Diário Oficial [do] Estado do Paraná, Curitiba, PR, 24 abr. 2012. Disponível em:

$<$ http://www.legislacao.pr.gov.br/legislacao/pesquisarAto $>$. Acesso em: 24 jun. 2013.

PARANÁ. Lei Complementar 149, de 22 de agosto de 2012. Institui a Região Metropolitana de Umuarama. Diário Oficial [do] Estado do Paraná, Curitiba, PR, 22 ago. 2012. Disponível em:

$<$ http://www.legislacao.pr.gov.br/legislacao/pesquisarAto $>$. Acesso em: 24 jun. 2013. 
PARANÁ. Secretaria de Estado de Meio Ambiente e Recursos Hídricos. Plano de Regionalização da Gestão Integrada de Resíduos Sólidos Urbanos do Estado do Paraná. Curitiba, 2013. Disponível em:

$<$ http://www.residuossolidos.sema.pr.gov.br/modules/documentos/ind ex.php?curent_dir=480>. Acesso em: 09 abr. 2013.

PATRÍCIO, Claudia Cartes; SILVA, Christian Luiz da. Aglomerações urbanas e geração de resíduos: um olhar sobre a região metropolitana de Curitiba - RMC. Percursos (Florianópolis. Online), v. 16, p. 122-142, 2015.

PINHO, Paulo Maurício. Avaliação dos Planos Municipais de Gestão Integrada de Resíduos Sólidos Urbanos na Amazônia Brasileira. 249 f. Tese (Programa de Pós-Graduação em Ciência Ambiental - Mestrado e Doutorado), Universidade de São Paulo, São Paulo, 2011.

SILVA, Christian Luiz da; FUGII, Gabriel Massao; BASSI, Nadia Schimdt; SANTOYO, Alain Hernández; VASCONCELOS, Marta Chaves. GESTÃO DE RESÍDUOS SÓLIDOS URBANOS EM CAPITAIS BRASILEIRAS ALTERNATIVAS PARA UM MODELO DE GESTÃO. Revista Brasileira de Ciências Ambientais, v. 33, p. 118-132, 2014.

SILVA, Christian Luiz da; FUGII, Gabriel Massao; MARINI, Marcos Junior. GESTÃO DA CADEIA DE RECICLAGEM EM REDE: UM ESTUDO DO PROJETO ECOCIDADÃO NO MUNICÍPIO CURITIBA. Desenvolvimento Regional em debate, v. 5, p. 20-37, 2015.

SILVA, Christian Luiz da; FUGIl, Gabriel Massao; BASSI, Nadia Schimdt; SANTOYO, Alain Hernández. O que é relevante para planejar e gerir resíduos sólidos? Uma proposta de definição de variáveis para a formulação e avaliação de políticas públicas. Biblio $3 w$ (Barcelona), v. XX, p. 1-25, 2015 a.

SILVA, Christian Luiz da; BIERNASKI, I. Políticas públicas de resíduos sólidos urbanos: uma análise de três metrópoles brasileiras. Revista Direito Empresarial (Curitiba), v. 12, p. 11-33, 2015b. 
SISTEMA NACIONAL DE INFORMAÇÕES SOBRE A GESTÃO DOS RESÍDUOS SÓLIDOS (SINIR). Consulta de Indicadores de Resíduos Sólidos Urbanos, 2010. Disponível em: <http://www.sinir.gov.br/web/guest/consultade-indicadores $>$ Acesso em: 26 jun. 2013.

Submetido em 22/01/2015

Aprovado em 09/04/2016

\section{Sobre os autores}

Priscila Alves dos Anjos

Mestre em Meio Ambiente Urbano e Industrial. Gestora Socioambiental da Companhia de Saneamento do Paraná (SANEPAR).

E-mail: priscilaa@sanepar.com.br

\section{Karen Juliana do Amaral}

Pesquisadora da Universidade de Stuttgart, Institute for Sanitary Engineering, Water Quality and Solid Waste Management (ISWA), e professora titular do Mestrado Internacional em Meio Ambiente Urbano e Industrial - MAUI).

E-mail: karen.amaral@iswa.uni-stuttgart.de

Klaus Martin Fischer

Pesquisador da Universidade de Stuttgart, ISWA, e professor titular do Mestrado Internacional em Meio Ambiente Urbano e Industrial - MAUI.

E-mail: klaus.fischer@iswa.uni-stuttgart.de 